\title{
The Use of Statistical Assumptions at Determining the Support Network Points
}

\author{
Tudor SĂLĂGEAN ${ }^{1}$, Paul SESTRAŞ ${ }^{1,2^{*}}$, Mircea ORTELECAN ${ }^{1}$, Dumitru ONOSE ${ }^{3}$, Adrian SAVU ${ }^{3}$, Raluca \\ Farcaş $^{4}$, Andra PORUȚIU ${ }^{1}$ \\ ${ }^{1}$ University of Agricultural Sciences and Veterinary Medicine Cluj-Napoca, Calea Mănăştur 3-5, \\ 400372, Cluj-Napoca, Romania, Phone: +40264.596.384, Fax: +40264.593.792 \\ ${ }^{2}$ University of Agronomic Sciences and Veterinary Medicine Bucharest, 59 Mărăşti Blvd, District 1, \\ 011464, Bucharest, Romania, Phone: +4021.318.25.64, Fax: + 4021.318.25.67 \\ ${ }^{3}$ Technical University of Civil Engineering Bucharest, Faculty of Geodesy, Department of Topography, \\ Lacul Tei 122-124, District 2, 020396, Bucharest, Romania \\ ${ }^{4}$ Technical University Cluj-Napoca, Faculty of Constructions, Department of Land Measurements and \\ Cadastre, Memorandumului 28, 400114, Cluj-Napoca \\ *)Corresponding author, e-mail: psestras@yahoo.com
}

BulletinUASVM Horticulture 72(2) / 2015

Print ISSN 1843-5254, Electronic ISSN 1843-5394

DOI:10.15835/buasvmcn-hort: 11580

\begin{abstract}
In many cases, the coordinates values of the support network, which were determined at different epochs, varies in the limit of measurement and calculation errors. In this case the problem is which of these points from the support network are fixed and which are displaced. The purpose of this paper is to establish the fixed points in the case of repeated measurements in a support network. Based on repeated measurements which were made in the support networks related to hydropower objectives, were used the statistical assumptions in order to determine the displacements of the points from one epoch to another. The instrumental observations in the support network were made with high precision total stations. Based on statistical verifications performed in the support network related to Drăgan Valley dam, from the eleven pillars, three pillars were established as fixed point. The statistics calculated for the other pillars is higher than the statistics extracted from tables, so these pillars could not be considered as fixed points. After the calculations, because the values of the point displacements from one epoch to another were very small, the determination of the pillars stability can only be achieved through statistical tests. The verification of the support network stability is extremely important because if the azimuthal measurements made on the tracking landmarks are made from station points which are displaced, then the coordinates of the tracking landmarks will be inaccurate.
\end{abstract}

Keywords: dam, displacement, landmark, support network.

\section{INTRODUCTION}

When designing tracking stations, related monitored objectives, it must be taken into account to ensure the accuracy required for determining the displacements of the sighting landmarks and also to ensure the stability of the stations during the entire period of observations (Ortelecan and Pop, 2005).

The exact determination of the observation stations displacements is required, because a wrong determination of the displacements may distort the shape deformations of the construction.

The accuracy of determining the sighting marks increases when the station are closer to the researched object. The observation stations are placed in the vicinity of the monitored construction, at distances that do not exceed 300$400 \mathrm{~m}$.

A necessary condition for accurate determi nation of absolute displacements of constructions 
is the stability of the geodetic points of observation (Kalkan et al., 2010; Wang and Yan, 2013).

In the case of tracking networks related to dams, in a first step is determined the stability of the network points and the accuracy for the stability determination. In the second step are determined the displacements of the sighting landmarks. The aim of this paper is to present only the first step.

Deformation measurements havean important status among various engineering surveying. The self-weight of a dam and the reservoir water pressure are primarily responsible for the increase of stresses within the dam body, which in time result in horizontal and vertical displacements, mostly of a permanent character.

\section{MATERIALS AND METHODS}

In the case of repeated measurements, we can speak of a change in the position of a point $P$, with a size DP and a mean error $\mathrm{S}_{\mathrm{DP}}$ (Moldoveanu, 2003) only if the inequality is satisfied:

$|\Delta P|>t_{k}\left|S_{\Delta P}\right|$

where:

$$
t_{k}=t(S, f)
$$

S - statistical significance;

$\mathrm{f}$ - number of additional measurements existing in the geodetic network;

$t_{k}$ - coefficient extracted from the tables of Student distribution.

Since the differences between the coordinates of the network points are very low, in the case of repeated measurements, in order to establish whether these differences are due to measurement errors or movement pillars will use statistical assumptions.

According to Danciu (2003), a statistical hypothesis is an assumption on the distribution characterizing a population or on the parameters of this distribution.

Usually it is operating with the null hypothesis $\left(\mathrm{H}_{0}\right)$, which is not known whether is true or false, and in case of a rejection of the null hypothesis there are used the alternative hypothesis $\left(\mathrm{H}_{1}, \mathrm{H}_{2}\right)$.

For verifying the statistical hypothesis the steps that need to be followed are:
- It is calculate the statistics q, depending on the measured values corresponding to a known distributions;

- It is specified the materiality threshold (a);

- Is established the null hypothesis $\left(\mathrm{H}_{0}\right)$ and the alternative hypothesis $\left(\mathrm{H}_{1}, \mathrm{H}_{2}\right)$;

- Is determined a critical value that is extracted from tables based on the materiality threshold and the volume of selection;

- It is accepted or rejected the null hypothesis, according to the calculated statistics (if it belongs or not to the critical region).

The statistical test corresponding to repeated measurements is called "global test of congruence of geodetic network" at the two measurement epochs (Niemeier, 1980), and has the following form:

$$
F_{H}=\frac{d^{T}\left(Q_{I}+Q_{I}\right)^{-1} d}{h s_{0}^{2}} .
$$

where:

$d=x_{I I}-x_{I}$

$\mathrm{d}$ - coordinates difference from epoch I and II

$Q_{i}=\left(B_{i}^{T} P_{i} B_{i}\right)^{-1} \quad i=I, I$.

$\mathrm{Q}_{\mathrm{i}}$ - weighting coefficients;

$\mathrm{B}_{\mathrm{I}}, \mathrm{B}_{\mathrm{II}}$ - configuration matrices at the two epochs

$s_{0}^{2}=\frac{v_{I}^{T} P_{I} v_{I}+v_{I}^{T} P_{I} v_{I}}{f_{1}+f_{2}}$

$f_{i}=n_{i}-u_{i}+d_{i}$

$h=d_{i}\left(Q_{I}+Q_{I}\right)$

$S_{0}^{2}$ - variance;

$\mathrm{V}_{\mathrm{I}}, \mathrm{V}_{\mathrm{II}}$ - measurement corrections in epoch I and II;

$\mathrm{f}_{1}, \mathrm{f}_{2}$ - degrees of freedom in the two epochs;

$n_{i}$ - number of measurements;

$u_{i}$-number of unknown elements;

$d_{i}$ - rank defect of the matrix $B_{I}$ and $B_{I I}$.

The null hypothesis used at verifying the stability of the support network points in the two measurement epochs will have the following form:

$$
H_{0}: x_{I}-x_{I}=0
$$

The value of the calculated statistics $\left(\mathrm{F}_{\mathrm{H}}\right)$ is compared with the tabelar value $\left(\mathrm{F}_{\mathrm{h}, \mathrm{f}, \mathrm{a}-\mathrm{a}}\right)$ extracted from the table of the Student distribution, getting 
on the null hypothesis the confirmation or infirmation of significant changes of coordinates of the point network from a measurement epoch to another.

In the case where

$$
P\left\{\mathrm{~F}_{\mathrm{H}}>\mathrm{F}_{\mathrm{h} f, 1-\alpha} \mid H_{0}\right\}=\alpha
$$

the hypothesis of equal coordinates in the two measurement epochs is admitted, so in the network do not occur significant displacements of the points.

The statistical calculations regarding the stability of the geodetic network will be based on the functional model and the statistical model written for two measuring epochs:

$$
\begin{aligned}
& {\left[\begin{array}{l}
\mathbf{m}_{\mathbf{I}}^{0} \\
\mathbf{m}_{\mathbf{I}}^{0}
\end{array}\right]+\left[\begin{array}{l}
\mathbf{v}_{\mathbf{I}} \\
\mathbf{v}_{\mathbf{I}}
\end{array}\right]=\left[\begin{array}{cc}
\mathbf{B}_{\mathbf{I}} & 0 \\
0 & \mathbf{B}_{\mathbf{I}}
\end{array}\right]\left[\begin{array}{l}
\mathbf{x}_{\mathbf{I}} \\
\mathbf{x}_{\mathbf{I}}
\end{array}\right]} \\
& C_{m m}=\underset{(12)}{\sigma_{0}^{2} Q_{m m}}=\sigma_{0}^{2}\left(\begin{array}{cc}
Q_{I} & 0 \\
0 & Q_{I I}
\end{array}\right)
\end{aligned}
$$

where:

$\mathbf{m}_{\mathbf{I}}^{0}, \mathbf{m}_{\mathbf{I}}^{0}$ - distinct measurements from epoch I and II;

$\mathrm{V}_{\mathrm{I}}, \mathrm{V}_{\mathrm{II}}$ - measurement corrections;

$\mathrm{B}_{\mathrm{I}}, \mathrm{B}_{\mathrm{II}}$ - configuration matrices at the two epochs; $\mathrm{X}_{\mathrm{I}}, \mathrm{X}_{\mathrm{II}}$ - point coordinates in the two epochs.

The case study was applied to the network related to Floroiu dam, located at the confluence of the creek Sebeşel and the creek Drăganului, Cluj county, Romania (Fig.1- situation before construction; Fig. 2 - after filling the lake).

The geodetic network for plannimetric tracking of the dam (Fig. 3) is formed of eleven pillars located downstream of the dam and are disposed as follows:

- six on the right bank of the valley - I, II, III, IV, X and XI;

- five on the left bank of the valley - V, VI, VII, VIII şi IX.

The coordinates of the network points are determined in a local coordinate system XOY, with the axes disposal as follows:

- the $\mathrm{X}$ axis is oriented on the direction downstream - upstream, with a growth sense of the coordinates towards the upstream.

- the $\mathrm{Y}$ axis is oriented on the direction right bank - left bank, with a growth sense of the coordinates towards the left bank.

In the planimetric network were made measurements with the total station Leica TS30, which has a accuracy for angular measurements of $0.5^{\text {cc }}$ and an accuracy for distance measurements of $0.6 \mathrm{~mm}+1 \mathrm{ppm}$.

The geodetic measurements in the planimetric network were achieved using the reiterated complete series method and the offsetting, in a first step, was treated as measurements in a free network.

In the network taken into study were performed 85 azimuthal observations from which

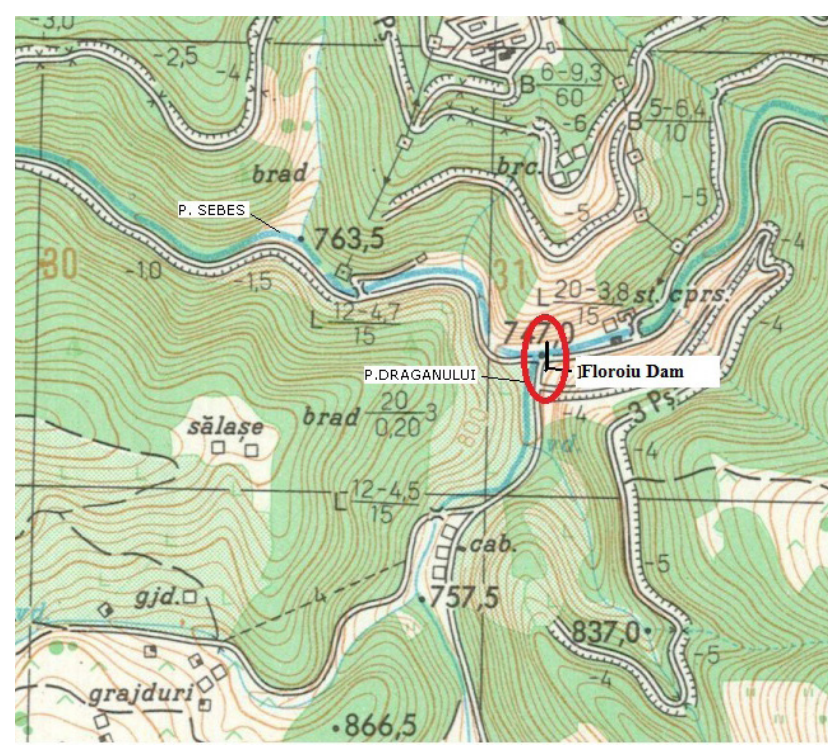

Fig. 1. Location dam Floroiu (source: map L-34-46-C-b) 
were removed the reciprocal visas VII-VIII and IIIX due to improper observations.

According to the method of indirect measurements, for each azimuthal observation it will be written a system of equations of corrections, therefore it will be obtained a system of 81 equations with 33 unknown elements, of which 22 unknown elements represent the coordinates variation of the network points and 11 unknown elements represent the orientations variation of the station points. By applying the equivalence rules 1 and 3 of Schreiber was obtained a system of 92 equations with 22 unknown elements, which has the following form:

$A X+l=V, \quad P$

where:

A - coefficient matrix;

$\mathrm{X}$ - the unknown elements of the system;

$\mathrm{l}$ - the free terms;

$\mathrm{V}$ - the measurement corrections.

$$
\begin{aligned}
& A_{92,22}=\left(\begin{array}{cccc}
a 1 & b 1 & \ldots & u 1 \\
a 2 & b 2 & \ldots & u 2 \\
\ldots & \ldots & \ldots & \ldots \\
a 92 & b 92 & \ldots & u 92
\end{array}\right) ; X_{22,1}= \\
& =\left(\begin{array}{c}
d x_{I} \\
d y_{I} \\
\ldots \\
d y_{X I}
\end{array}\right) ; l_{92,1}=\left(\begin{array}{c}
l_{1} \\
l_{2} \\
\ldots \\
l_{92}
\end{array}\right) ; V_{92,1}=\left(\begin{array}{c}
V_{1} \\
V_{2} \\
\ldots \\
V_{92}
\end{array}\right) \\
& P_{92,92}=\left(\begin{array}{cccc}
1 & 0 & \ldots & 0 \\
0 & 1 & \ldots & 0 \\
\ldots & \ldots & \ldots & \ldots \\
0 & 0 & \ldots & -1
\end{array}\right)
\end{aligned}
$$

ai, bi, ...ui - dirrection coefficients calculated with the provisional coordinates from the basis measurement;

$\mathrm{P}=-1$ - for the sum equations.

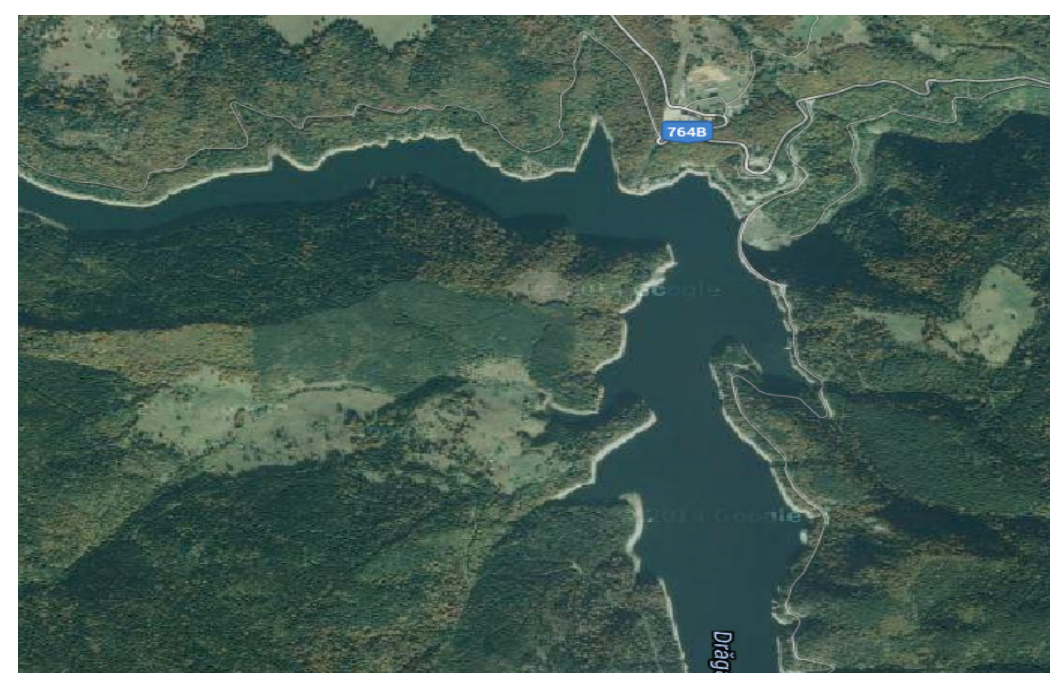

Fig. 2. The accumulation lake and the dam ( source: https://maps.google.ro/)

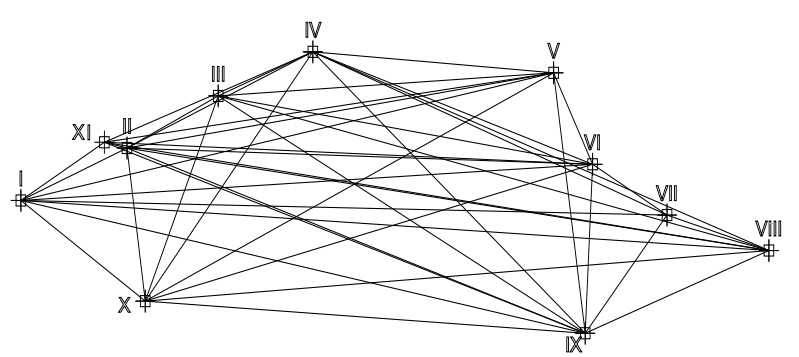

Fig. 3. Sketch of the microtriangulation network with the directions observed 
Since the normal system of equations of the form (16), has the normal coefficient matrix as singular, solving the system was performed by the Mittermayer method (relation 17):

$$
\begin{aligned}
& \left(A^{T} P A\right) X+A^{T} P l=0 \\
& X=-N(N N)^{-1} A^{T} P l
\end{aligned}
$$

where:

$$
\mathrm{N}=\mathrm{A}^{\mathrm{T}} \mathrm{PA}
$$

The standard deviation of weight unit is calculated with relation 18 :

$$
\begin{aligned}
& s_{0}=\sqrt{\frac{v^{T} P v}{n-u+d}} \\
& \text { where: } \\
& \mathrm{n} \text { - number of equation; } \\
& \mathrm{u} \text { - number of unknown elements; } \\
& \mathrm{d} \text { - the rank defect. }
\end{aligned}
$$

In the case of free networks, the correlation matrix of the unknown elements is determined with relation 19 and the standard deviation of the unknown elements is determined with relation 20:

$$
\begin{aligned}
& Q_{X}^{l}=-N(N N)^{-1} N(N N)^{-1} N \\
& S_{x_{k}}=\sigma_{0} \sqrt{Q_{k k}}
\end{aligned}
$$

\section{RESULTS AND DISCUSSIONS}

After solving the normal system of equations by the Mittermayer method (relations $16 \div 20$ ), were obtained the values of the coordinates support network corrections and the precision indices (Table 1).

Since the provisional values of the support network coordinates were considered as values of the coordinates obtained in the basis measurement, the corrections ,dx', dy' represent the displacements of points on both directions, from the basis measurement to the current measurement and $\mathrm{dp}$ represent the linear displacement of the points.

The mean square error of unit weight , $\mathrm{S}_{0}{ }^{\prime}$ (standard deviation) is calculated from equation 18 and reflects the internal precision of the network if the network is considered free and has a value of $10.6 \mathrm{~mm}$. The mean square errors of the unknown elements $\left(S_{x}, S_{y}\right)$ were calculated with equation 20 are shown in Table 1.

Because the mean errors of the coordinates $\left(\mathrm{S}_{\mathrm{x}}, \mathrm{S}_{\mathrm{y}}\right)$ change their value when changing the coordinate system, the local accuracy is expressed through the errors ellipâse which is an invariant of the matrix of covariance, which does not depend on the system of axes of coordinates, the ellipse parameters depend on the geodetic network configuration and the measurement accuracy.

The parameters of the error ellipse represent a reliable domain for planimetric position of a point, and their values for the network taken into study are presented in Table 2 .

After calculating the $\mathrm{F}_{\mathrm{H}}$ statistics with relation 3 was obtained the value 5.26 . The tabular value $\left(F_{h f, 1-\mathrm{a}}\right)$ extracted from the Student distribution

Tab. 1. Values of the coordinates support network corrections and the precision indices

\begin{tabular}{ccccccc}
\hline Point & $\mathrm{dx}[\mathrm{mm}]$ & $\begin{array}{c}\mathrm{dy} \\
{[\mathrm{mm}]}\end{array}$ & $\begin{array}{c}\mathrm{dp} \\
{[\mathrm{mm}]}\end{array}$ & Sx $[\mathrm{mm}]$ & Sy $[\mathrm{mm}]$ & $\begin{array}{c}\text { Sp } \\
{[\mathrm{mm}]}\end{array}$ \\
\hline I & -1.46 & -1.95 & 2.44 & 0.27 & 0.92 & 0.96 \\
\hline II & -0.99 & -3.14 & 3.29 & 0.37 & 0.22 & 0.43 \\
\hline III & 3.06 & 3.88 & 4.94 & 0.33 & 0.50 & 0.60 \\
\hline IV & 3.64 & -1.37 & 3.89 & 0.20 & 0.36 & 0.41 \\
\hline V & 3.84 & 2.61 & 4.64 & 0.29 & 0.30 & 0.41 \\
\hline VI & 3.01 & 4.38 & 5.32 & 0.35 & 0.23 & 0.42 \\
\hline VII & 4.07 & 6.39 & 7.58 & 0.39 & 0.23 & 0.46 \\
\hline VIII & -16.87 & -18.71 & 25.19 & 0.57 & 0.80 & 0.98 \\
\hline IX & 0.33 & 7.05 & 7.06 & 0.30 & 0.34 & 0.46 \\
\hline X & 0.30 & -2.97 & 2.99 & 0.80 & 0.41 & 0.90 \\
\hline XI & 1.07 & 3.83 & 3.97 & 1.20 & 1.15 & 1.66 \\
\hline
\end{tabular}


Tab. 2. The parameters of the error ellipse

\begin{tabular}{cccc}
\hline Point & $\mathrm{a}[\mathrm{mm}]$ & $\mathrm{b}[\mathrm{mm}]$ & $\theta$ \\
\hline $\mathrm{I}$ & 1.4 & 0.3 & 100.7461 \\
\hline $\mathrm{II}$ & 1.4 & 0.2 & 99.2331 \\
\hline $\mathrm{III}$ & 1.4 & 0.2 & 99.2190 \\
\hline $\mathrm{IV}$ & 1.1 & 0.1 & 99.2206 \\
\hline $\mathrm{V}$ & 1.3 & 0.2 & 100.7845 \\
\hline $\mathrm{VI}$ & 1.4 & 0.2 & 99.6447 \\
\hline VII & 1.5 & 0.2 & 100.7779 \\
\hline VIII & 1.9 & 0.4 & 99.2192 \\
\hline $\mathrm{IX}$ & 1.3 & 0.1 & 99.2158 \\
\hline $\mathrm{X}$ & 2.2 & 0.4 & 199.2281 \\
\hline $\mathrm{XI}$ & 2.8 & 0.2 & 0.7851 \\
\hline
\end{tabular}

Tab. 3. Values of indices of significance a (Student distribution)

\begin{tabular}{cccc}
\hline Indice of significance $\alpha$ & $5 \%$ & $1 \%$ & $0,10 \%$ \\
\hline Tabular values & 1,98 & 2,62 & 3,37 \\
\hline
\end{tabular}

table, by reference to indices of significance a have values present in Table 3:

Based on the values obtained in accordance with relation 10, the assumption of equal coordinates in the two measurement epochs is permissible, so the microtriangulation network is stable.

\section{CONCLUSION}

Considering the network configuration and the number of observations similar in the two measurement epochs, it can be concluded that in the network have not been any point displacements which are statistically significant.

In the case of monitoring networks related to dams, the network configuration remains the same for all the measurement epochs. The only thing that can change, due to visibility reasons, is the number of measurements made in different epochs.

The smallvalues of the error ellipse parameters (1-2 $\mathrm{mm})$ indicates that the instrumental observations were carried out with precision.

Since the displacements of the support network points are determined from the values of coordinates from the basis measurement, and these measurements are considered provisional values, the corrections obtained from processing the indirect measurements are the displacements of the points on the two axes.

\section{REFERENCES}

1. Ghițău D. (1983). Geodesy and gravimetric geodesy. Didactic and Pedagogic Publishing House, Bucharest, Romania.

2. Kalkan Y., Alkan R., Bilgi S. (2010). Deformation Monitoring Studies at Ataturk Dam. Proceedings of the XXIV FIG Congress "Facing the Challenges - Building the Capacity", 11-16 April 2010, Sydney, Australia, ISBN 97887-90907-87-7: 10-24.

3. Moldoveanu C. (2002). Geodesy. Matrix Rom Publishing House, Bucharest, Romania.

4. Niemeier W. (1980). Ausgleichung geodatischer Netze. GNLI Publishing House, Stuttgart, Germany.

5. Ortelecan M., Pop N. (2005). Topographical methods for monitoring of constructions and surrounding lands. AcademicPres Publishing House, Cluj-Napoca, Romania.

6. Wang X., Yan Y.M. (2013). Research Status Summary on Dam Security Monitoring. Applied Mechanics and Materials, vol.405-408: 2473-2476. 